\title{
An Analysis of the Conversational Implicature of "Little Sheldon" from the Perspective of Violation of the Cooperative Principle
}

\author{
Shuyan Zhao \\ Tiangong University, Tianjin, China \\ Email: zhaoshuyan5@126.com
}

How to cite this paper: Zhao, S.Y. (2021) An Analysis of the Conversational Implicature of "Little Sheldon" from the Perspective of Violation of the Cooperative Principle. Open Access Library Journal, 8: e7115.

https://doi.org/10.4236/oalib.1107115

Received: December 27, 2020

Accepted: January 19, 2021

Published: January 22, 2021

Copyright $\odot 2021$ by author(s) and Open Access Library Inc.

This work is licensed under the Creative Commons Attribution International License (CC BY 4.0).

http://creativecommons.org/licenses/by/4.0/

\section{(c) (i) Open Access}

\begin{abstract}
Grice, H. P., an American linguist, first proposed the Cooperative Principle in 1967, which is an indispensable part of pragmatics. Grice believes that people make more or less efforts for cooperation in order to achieve the purpose of conversation in daily conversation. Sometimes they deliberately violate the Cooperative Principle and produce special Conversational Implicature. This paper analyzes a few dialogues in Little Sheldon from the perspective of violating the Cooperative Principle to explore the actual conversational meaning and illocutionary meaning behind the dialogues.
\end{abstract}

\section{Subject Areas}

Linguistics

\section{Keywords}

Cooperative Principle, Conversational Implicature, Little Sheldon

\section{Introduction}

Pragmatics is a new field of linguistics. It mainly studies how to understand and use language in context, and how to use language successfully. Nowadays, with the development of new media, the corpus of pragmatics has been greatly enriched. Conversational Implicature and Cooperative Principle are two core concepts in pragmatics, which have been the focus of research. The corpus of Conversational Implicature and Cooperative Principle has gradually transferred from theory to daily dialogue, and then to dialogues in movies and TV plays. Most of the studies on Little Sheldon are conducted from the perspective of verbal humor or subtitle translation. With the development of cultural globaliza- 
tion, American drama, as one of many cultural communication products, has become an important way for us to deeply understand American culture. In this case, subtitle translation strategy is particularly important [1]. This paper analyzes how to produce humorous effect by violating the Cooperative Principle, which can help English learners improve their ability to appreciate English humor [2]. Subtitle translation plays an important role in cultural exchange. But exploring the actual conversational implicature behind the dialogue is a deeper collision with culture. At present, there are few studies on Little Sheldon combining cooperative principle with conversational implicature in China.

Compared with the Big Bang Theory, Little Sheldon's dialogue is more about family life and school life. Children and adults tend to have more conflict talk and dialogue that violates the Cooperative Principle, so the dialogue in Little Sheldon has high research value. This paper takes the dialogues in Little Sheldon as the object, combines the theory of Conversational Implicature and context, analyzes the application of Cooperative Principle in American TV dialogues, and explores the semantic effects that the characters really want to express, so as to enable the audience to better experience and understand the emotion conveyed by the dialogue, so as to achieve the purpose of cultural exchange.

\section{Grice's Cooperative Principle and Conversational Implicature Theory}

\subsection{Principle of Cooperation}

The conversational principle is also called cooperative principle (CP), which was put forward by American language philosopher Grice in his speech at Harvard University in 1967, also known as Grice's principle. Grice believes that in the process of communication, in order to achieve a specific purpose, the speaker and the hearer seem to follow a certain principle intentionally or unintentionally in order to cooperate effectively to complete the communication task. If one side of the communication does not comply with the "cooperative principle", it may produce two different results: either the communication will be terminated, or the speaker intends to express some implied meaning. Therefore, the hearer should correctly consider the real intention of the speaker and understand its real meaning, so as to make the communication go on smoothly. In his article "logic and conversation", Grice thinks that the Cooperative Principle that people abide by in conversation includes four categories, and each category includes a criterion and some sub criteria [3]:

1) Maxim of Quantity:

a) Make your communication information as much as needed (for the current purpose of the exchange).

b) Do not make your communication information more than is needed.

2) Maxim of Quality: try to make your communication information that is true.

a) Do not say you don't have enough evidence. 
b) Do not say that for which you lack sufficient evidence.

3) Maxim of Relation: discourse should be relevant.

4) Maxim of Manner: be perspicuous.

a) Avoid obscurity of expression.

b) Avoid ambiguity.

c) Be brief (avoid unnecessary prolixity).

d) Be orderly.

\subsection{Conversational Implicature Theory}

The cooperative principle allows the meaning of various sentences and contexts to be mixed into the meaning of utterance, so that the contextual meaning becomes conversational meaning. The reason why conversational implicature comes into being is that in actual communication, for various reasons, the Cooperative Principle and the standards involved are not absolutely observed. It does not study the meaning of language itself from the interior of the language system (phonetics, grammar, semantics, etc.), but studies the real meaning of discourse from the relevance of context and discourse, and explains the implied meaning of discourse.

\section{The Conversational Implicature of Violating Cooperative Principle in Little Sheldon}

Little Sheldon is a sitcom and a derivative of the Big Bang Theory. It mainly tells a series of stories about Sheldon Cooper in family and school in eastern Texas. Nine years old Sheldon (Ian Armitage) jumps directly to senior high school. At this time, although he is still young, he can do his homework well, but his life experience and EQ are much worse than those of these senior high school students. In addition to the strange clothes of his classmates, he also criticizes the mistakes made by old teachers in teaching, which makes several teachers feel that they can't go on in class. At this time, as a father, George can only tell him the truth of the adult world in advance. He knows that although his son is right, not everyone in the world will abide by the rules, and not everything will be as one's wishes.

This paper selects some dialogues in Little Sheldon to analyze how and why the characters violate the four principles of cooperative principle, and analyzes the conversational implicature after deliberately violating the Cooperative Principle.

\subsection{Violation of Quantity Criterion}

The principle of quantity requires that utterances should contain the information needed for conversation, but not more than the information needed. Therefore, the violation of the quantity criterion includes two situations: insufficient or redundant information. When people provide more or less information than they actually need, conversational implicature may occur [4]. 


\section{Example 1:}

Sheldon: Georgie, did you wash your hands before dinner? Or even this week? Georgie: None of your business.

Sheldon: Hence the mittens.

Analysis: A conversation between Sheldon and his brother, George Jr., as the Sheldon family hold hands and say Grace before dinner. Sheldon's question was a simple yes or no question, and George's answer was a simple yes or no question to satisfy the quantitative criterion. But instead of answering the question directly, George said, "None of your business" and George's response was not informative enough to violate the rule of quantity. The implication of George's conversation was that he didn't wash his hands and didn't answer Sheldon's questions directly. Sheldon replied, so wear gloves, and here Sheldon also violated the quantity rule, giving too much information. The implication was that Sheldon had acquiesced to George not washing his hands before meals and had chosen to wear gloves to hold hands for sanitary reasons.

\subsection{Violation of Quality Criterion}

The quality standard requires that what is said should be true. Therefore, it is against the quality standard to provide information which is false and lacks sufficient evidence [5]. Some scholars believe that some rhetorical devices, such as irony, exaggeration and metaphor, are caused by the violation of the quality criterion, which makes the language more vivid and appealing.

\section{Example 2:}

Sheldon: I was exploring dimensional kinematics.

Georgie: Admit it, he's adopted.

Sheldon: How can I be adopted when I have a twin sister? Think, monkey, think.

Analysis: The conversation took place before the Sheldon family had dinner. Father asked Sheldon what he was up to. Sheldon replied that I was studying kinesiology. The background of the play is the gifted young Sheldon, who has been studying physics since he was a child. He has achieved excellent results compared with his brothers and sisters. That's why Georgie Said Sheldon was adopted. Here little George violated the quality standard. Little George knew that Sheldon was his own brother, but said Sheldon was adopted. The implication is that Sheldon doesn't fit in with the ordinary people in his family. Sheldon didn't deny it directly. Instead, he called little George a monkey and asked him to think about it. Here Sheldon violates both the quantity rule and the quality rule. Sheldon knew little George was not a monkey, but he replied in this way, which implied that he mocked little George's intelligence quotient in order to fight back his malice.

\subsection{Violation of Relation Criterion}

Relevance criterion requires the content of discourse to be relevant. Once discourse leaves the subject of communication, it violates the relevance criterion 
[6].

\section{Example 3:}

Mom: Speaking of God, who's going to church with me tomorrow? Georgi?

Georgie: I got to study my playbook.

Analysis: The dialogue took place between George and his mother. His mother wanted everyone to go to church to pray and asked who would like to go together. George didn't directly answer yes or no, but said that there were plans for tomorrow. The implication was that he refused to go to church with his mother. Here little George broke the rules of relevance.

\subsection{Violation of Manner Criterion}

The manner criterion requires that the utterance should be clear, concise and accurate. The implication, complexity and ambiguity of the expression is a violation of the norms of manner [7].

\section{Example 4:}

Mom: It's got to be here.

Sheldon: It's not. It's not.

Mom: Shelly, stay calm. We'll find it.

Sheldon: My tie is gone! My tie is gone!

Mom: Shelly, you don't really need a tie.

Sheldon: I have to find my tie. I have to find my tie.

Analysis: This conversation takes place between Sheldon and his mother. Sheldon can't find the bow tie to wear to school. In the dialogue, Sheldon constantly repeats his words. Here, Sheldon violates the principle of way and should have kept his words clear. The implication is that Sheldon is very excited because he can't find a bow tie and repeats his words to express his anxiety.

\section{Conclusion}

To sum up, following the Cooperative Principle in verbal communication is conducive to the smooth progress of conversation. However, more attention should be paid to the conversational implicature produced by violating the Cooperative Principle, because these utterances contain more important pragmatic implicatures. Grice's cooperative principle of conversation is only an assumption in the ideal context. There is no clear boundary between the four principles of cooperative principle and their sub criteria, and they often overlap each other in the actual context. In real social communication, there are countless cases of intentional violation of the Cooperative Principle, which will not affect the communication, but can achieve unexpected communication effect. The dialogue of characters in films and TV plays also follows certain Cooperative Principles. There are many dialogues violating the Cooperative Principle in the American drama Little Sheldon. Using the Cooperative Principle in pragmatics to analyze the dialogue between the characters can help the audience more deeply understand the emotions expressed in the dialogue and also let us know more about the West. 


\section{Conflicts of Interest}

The author declares no conflicts of interest regarding the publication of this paper.

\section{References}

[1] Zhang, Q. (2020) Ideological Differences between Chinese and American Subtitles of American TV Series: A Case Study of Little Sheldon. Research on Transmission Competence, 12, 28-29.

[2] Dong, L.F. (2018) An Analysis of Humor in Little Sheldon from the Perspective of Cooperative Principle. Campus English, 30, 217-218.

[3] Grice, H.P. (1975) Logic and Conversation. In: Cole, P. and Morgan, J., Eds., Syntax and Sematics3: Spech Acts, Academic Press, New York.

[4] He, Z.R. (2000) Pragmatics and English Learning. Shanghai Foreign Language Education Press, Shanghai.

[5] He, Z.R. (2003) Notes on Pragmatics. Nanjing Normal University Press, Nanjing.

[6] He, Z.X. (2005) A New Introduction to Pragmatics. Shanghai Foreign Language Education Press, Shanghai.

[7] He, Z.R. and Ran, Y.P. (2006) A Survey of Pragmatics. Hunan Education Publishing House, Hunan. 